\title{
Differential expression of Cathepsin $S$ and $X$ in the spinal cord of a rat neuropathic pain model
}

\author{
Anna Leichsenring*1, Ingo Bäcker ${ }^{1}$, Wiebke Wendt ${ }^{2}$, Michael Andriske ${ }^{1}$, \\ Beate Schmitz ${ }^{2}$, Christine C Stichel ${ }^{2}$ and Hermann Lübbert ${ }^{1,2}$
}

\begin{abstract}
Address: ${ }^{1}$ Department of Animal Physiology, Ruhr-University of Bochum, Bochum, Germany and 2Biofrontera Bioscience GmbH, Leverkusen Germany

Email: Anna Leichsenring* - anna.leichsenring@rub.de; Ingo Bäcker - ingo.baecker@rub.de; Wiebke Wendt - wwendt@biofrontera.com; Michael Andriske - michael.andriske@rub.de; Beate Schmitz - bschmitz@biofrontera.com; Christine C Stichel - c.stichelgunkel@biofrontera.com; Hermann Lübbert - hluebbert@biofrontera.com

* Corresponding author
\end{abstract}

Published: 12 August 2008

BMC Neuroscience 2008, 9:80 doi:10.1 /86/147|-2202-9-80
Received: 14 February 2008

Accepted: 12 August 2008

This article is available from: http://www.biomedcentral.com/I47I-2202/9/80

(C) 2008 Leichsenring et al; licensee BioMed Central Ltd.

This is an Open Access article distributed under the terms of the Creative Commons Attribution License (http://creativecommons.org/licenses/by/2.0), which permits unrestricted use, distribution, and reproduction in any medium, provided the original work is properly cited.

\begin{abstract}
Background: Ample evidence suggests a substantial contribution of cellular and molecular changes in the spinal cord to the induction and persistence of chronic neuropathic pain conditions. While for a long time, proteases were mainly considered as protein degrading enzymes, they are now receiving growing interest as signalling molecules in the pain pathology. In the present study we focused on two cathepsins, CATS and CATX, and studied their spatiotemporal expression and activity during the development and progression of neuropathic pain in the CNS of the rat $5^{\text {th }}$ lumbar spinal nerve transection model (L5T).

Results: Immediately after the lesion, both cathepsins, CATS and CATX, were upregulated in the spinal cord. Moreover, we succeeded in measuring the activity of CATX, which was substantially increased after L5T. The differential expression of these proteins exhibited the same spatial distribution and temporal progression in the spinal cord, progressing up to the medulla oblongata in the late phase of chronic pain. The cellular distribution of CATS and CATX was, however, considerably different.
\end{abstract}

Conclusion: The cellular distribution and the spatio-temporal development of the altered expression of CATS and CATX suggest that these proteins are important players in the spinal mechanisms involved in chronic pain induction and maintenance.

\section{Background}

Neuropathic pain is one type of chronic pain and originates by definition from a lesion of the nervous system (for reviews see $[1,2]$ ). It is a devastating and difficult to manage disease mainly because the underlying mechanisms are still poorly understood. Indeed, several types of cells and highly complex interactions of multiple pathways have been implicated in the pathogenesis (for reviews see $[1,3,4])$. In this context work on animal models has emphasized the important contribution of differences in protein expression to neuropathic pain induction and maintenance (for reviews see [5-7]). Within this cocktail proteases are receiving growing interest [8-12] because of their enormous destructive potential and the irreversibility of their action (for reviews see [13-16]). 
In our study we focus on a distinct group of proteases, the cathepsins (CAT), which are cysteine proteases mainly localized in lysosomes/peroxisomes but are also found in extralysosomal sites [17]. There are 11 human members (cathepsins $\mathrm{B}, \mathrm{C}, \mathrm{F}, \mathrm{H}, \mathrm{K}, \mathrm{L}, \mathrm{O}, \mathrm{S}, \mathrm{V}, \mathrm{W}$ and $\mathrm{X}$ ) and in mouse 8 additional members (cathepsins 1, 2, 3, 6, J, M, $\mathrm{Q}$ and $\mathrm{R}$ ) in this group of enzymes $[18,19]$. They play a vital role in normal cellular protein metabolism such as the regulation of key protein kinases and phosphatases, and the induction of specific cytoskeletal rearrangements, which may account for their involvement in intracellular signaling, vesicular trafficking, and structural stabilization $[20,21]$. Hence, it is not suprising that CAT are implicated in the manifestation of a number of diseases, including cancer, arthritis, Morbus Parkinson, Morbus Alzheimer and age-dependent inflammation [22-27]. Recent studies suggest that the activation or breakdown of the endosomal/lysosomal proteolytic system might also be involved in pain pathophysiology. Thus, in different chronic animal pain models an upregulation of some members $(\mathrm{S}, \mathrm{B}, \mathrm{H}, \mathrm{L}, \mathrm{D})$ of the CAT family along the ascending nociceptive pathway has been reported $[9,10]$ and CATS has even been implicated in neuropathic hyperalgesia and allodynia $[11,28]$.

With these strong implications for a role of CAT in neuropathic pain pathogenesis in mind we decided to study the spatiotemporal expression pattern of two of these proteases, the CATS and the more recently identified CATX, during the phases of pain induction and maintenance in a rat neuropathic pain model, the transection of the $5^{\text {th }}$ lumbar spinal nerve. CATS is a well-described cathepsin originally identified from lymph nodes and spleen $[29,30]$ and is well known for its crucial function in the control of antigen presentation [31]. CATX, on the other hand, has only recently been localized in the central nervous system [26] and its expression pattern in pathological situations implies a role in degenerative processes $[27,32]$.

\section{Results \\ Cellular and spatiotemporal expression of CATS and CATX in normal and L5T spinal cord}

In unlesioned adult rats CATS- and CATX-immunoreactivities were found in cells of both grey and white matters (Fig. 1) throughout the entire length of the spinal cord. Most CATS-immunopositive cells were of small size and distributed uniformely (Fig. 1A, C, E, F). While CATSimmunopositive neurons were rare, CATX-immunoreactivity was found in nearly all neurons (Fig. 1B, D, H) and only in few small cells (Fig. 1D, J). The immunoreactivities were associated with spherical granules within the cytoplasm of cells, sparing the nucleus (Fig. 1E, D, H).

The first changes of CATS- and CATX-immunoreactivities were already notable $1 \mathrm{~d}$ after L5T. For both proteins we observed upregulations that were restricted to the ipsilateral fasciculus gracilis, the dorsal horn and layer IX in the ventral horn in the lumbar segment (Figs. 2 and 3). Within these regions, the number of small CATS- as well as CATX-immunopositive cells increased substantially (Fig. 2). Moreover, we found a numerical increase in CATS-immunopositive neurons, while the number of CATX-immunopositive neurons was constant. Interestingly, numerous small CATS as well as CATX-immunopositive cells engulfed large motoneurons in the ventral horn (Fig. 2G, I). Within the following days the ipsilateral increase in immunopositive cells in the fasciculus gracilis spread caudocranially to the upper SC segments and reached the gracile nucleus at $1 \mathrm{w}$ after injury (Figs. $2 \mathrm{~L}, \mathrm{~N}$ and 3). At that time-point this nucleus exhibited morphological signs of degeneration (data not shown).

\section{Upregulation of CATS and CATX protein levels and increase in enzyme activities}

We next demonstrated that the changes in CATS- and CATX-immunoreactivities are reflected by changes in the levels of the respective proteins and, above all, that these are also reflected by a change of activity. Therefore, we first analyzed the protein levels of CATX and CATS in the spinal cord of sham versus L5T animals at $8 \mathrm{~d}$ after injury, a time point when the increase in immunoreactivities in the spinal cord was at its maximum (Fig. 3).

Western blot analysis ( $\mathrm{n}=5$ per group) revealed the proforms of CATS (37 kD) and CATX (34 kD), as the most prominent bands, while the prepro- and mature forms were below the detection level. The proforms of both enzymes were detected in all segments analyzed (L, lumbar; $\mathrm{T}$, thoracic; $\mathrm{C}$, cervical) of the adult rat spinal cord (Fig. 4A). The L5 nerve transsection produced an upregulation in all SC segments for CATS as well as CATX (Fig. $4 \mathrm{~A})$. The strongest increase in protein content was found in the T segment for both enzymes (CATS 63.6\%; CATX $87.4 \%$ ), while the increase in the $\mathrm{L}$ and $\mathrm{C}$-segments was substantial (34-61.5\%) but lower than in the T segment (Fig. 4A). Moreover, our Western blot analysis showed that in all SC segments the level of CATX is more than twice as high as the level of CATS. These results were confirmed in a second experiment with 4 animals per group (see Additional files 1 and 2).

This data is supported by measurements of CATX activity. CATS activity assays were not performed since the assay suffered from the lack of a specific substrate and a specific commercially available inhibitor for the enzyme, leaving doubts about the specificity of the assay in complex protein mixtures. At $8 \mathrm{~d}$ after L5T CATX activity increased strongly and highly significant $(\mathrm{p} \leq 0.001)$ in the lumbar segment (Fig. 4B; 59\% compared to sham, 90\% compared 


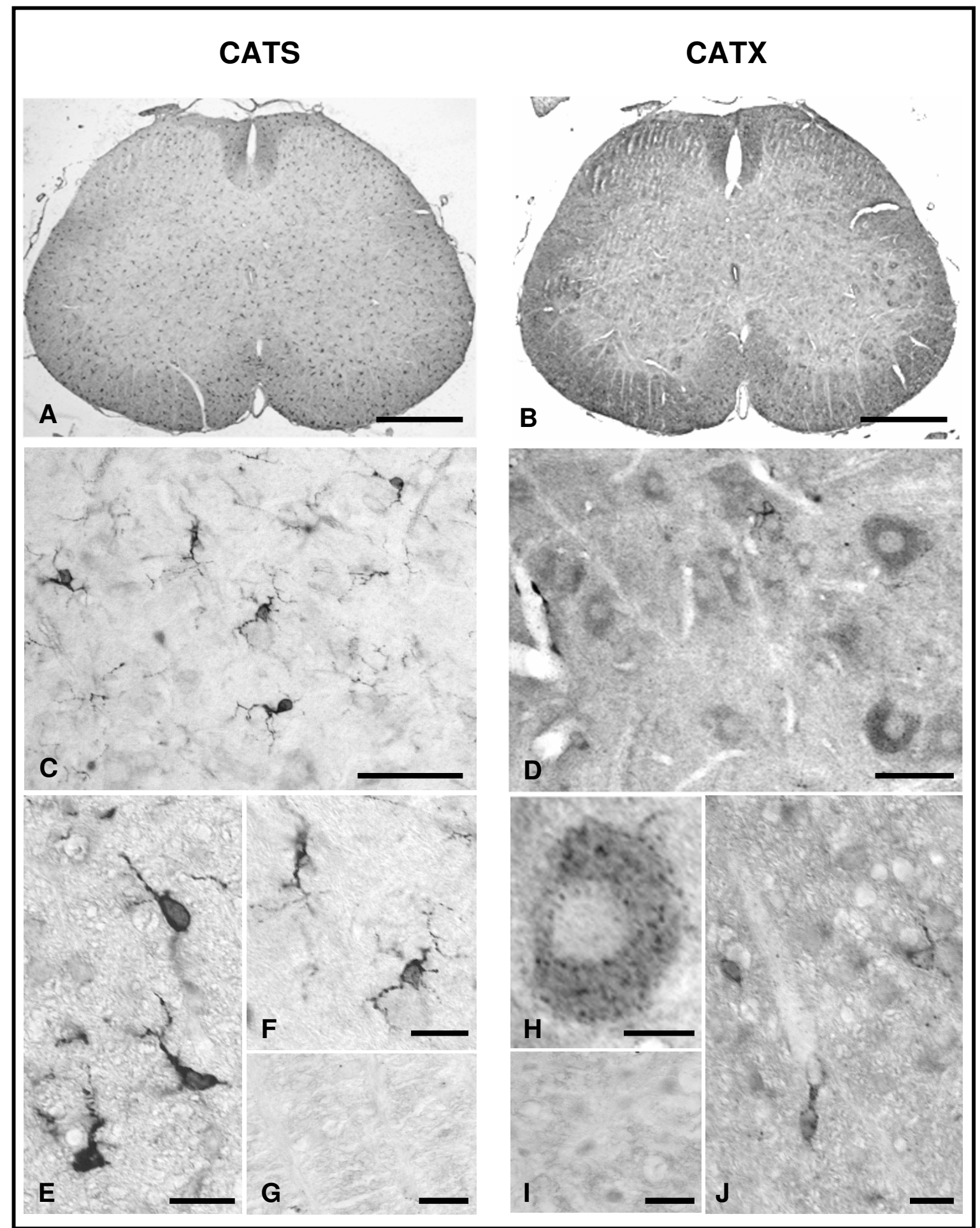

Figure I

CATS- and CATX-immunohistochemistry in normal rat spinal cord. Representative examples of CATS- (A, C, E-G) and CATX-immunostained (B, D, H-J) sections of the $L 5$ segment. CATS-immunopositive deposits are localized in small gliallike cells (C, E, F) that distributed homogenously throughout the section (A), while CATX is mostly found in large neurons (D, $H$ ) and only few small cells are intensely stained $(D, J)$. G, I: Sections incubated with preabsorbed primary antibodies are free of immunostaining. Scale bars, $500 \mu \mathrm{m}$ (A, B), $50 \mu \mathrm{m}$ (C, D), $20 \mu \mathrm{m}$ (E-J). 


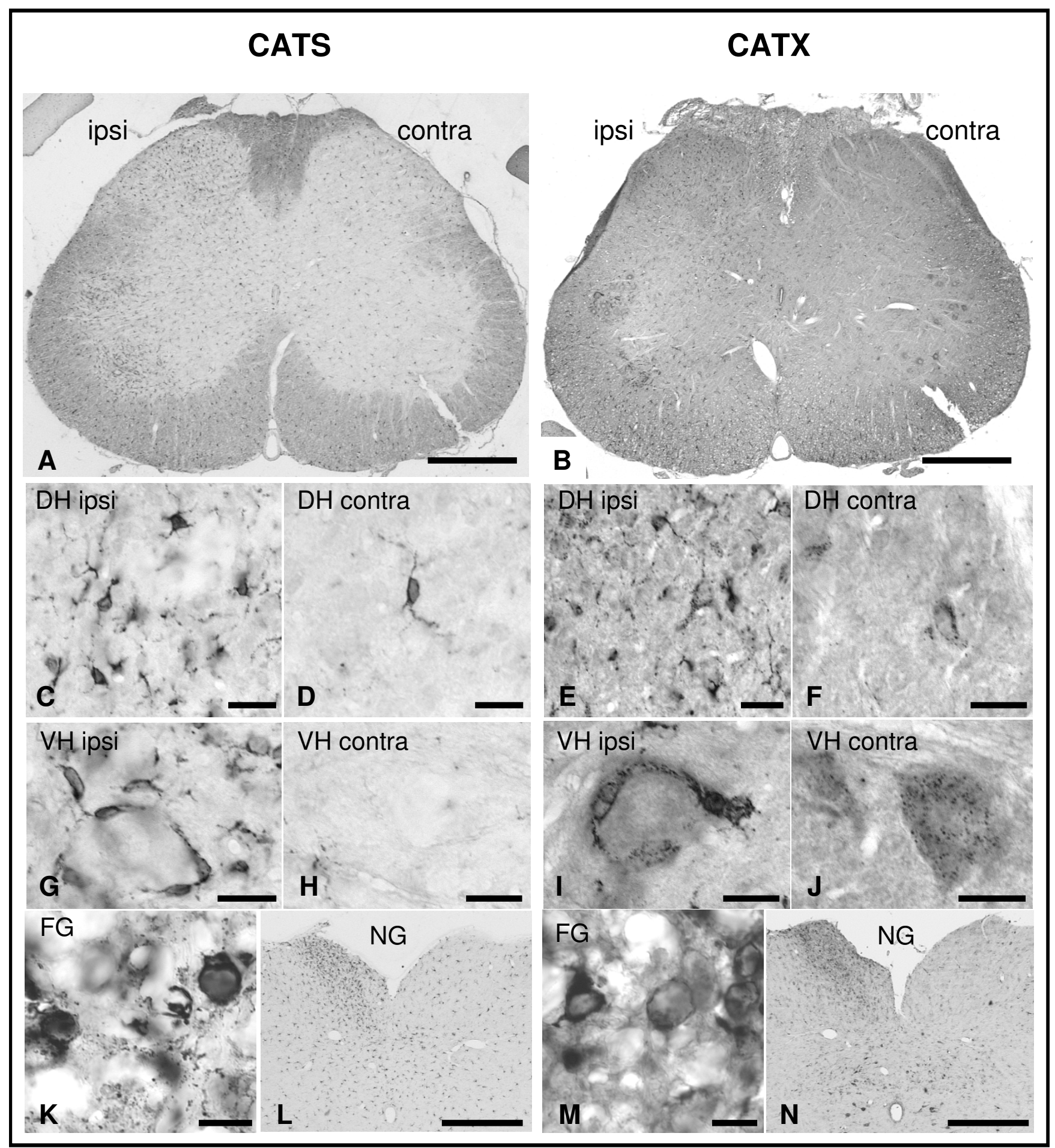

\section{Figure 2}

Upregulation of CATS- and CATX-immunoreactivities in the spinal cord at I4 d after L5T. Survey micrographs illustrate the ipsilateral increase of CATS- and CATX-immunoreactivity in whole spinal cord sections (A, B), in the dorsal horn $(\mathrm{DH})(\mathrm{C}-\mathrm{F})$, the layer $\mathrm{IX}$ of the ventral horn $(\mathrm{VH})$ and the fasciculus gracilis (FG). In the FG immunopositive cells exhibit macrophage-like morphology $(\mathrm{K}, \mathrm{M})$ and in the $\mathrm{VH}$ small immunopositive cells engulf motoneurons (G, I). At this time point the ipsilateral nucleus gracilis exhibits more intense CATS- $(\mathrm{L})$ and CATX-staining $(\mathrm{N})$ than the contralateral side. Scale bars, 500 $\mu \mathrm{m}(\mathrm{A}, \mathrm{B}, \mathrm{L}, \mathrm{N}), 20 \mu \mathrm{m}(\mathrm{C}-\mathrm{J}), 10 \mu \mathrm{m}(\mathrm{K}, \mathrm{M})$. 


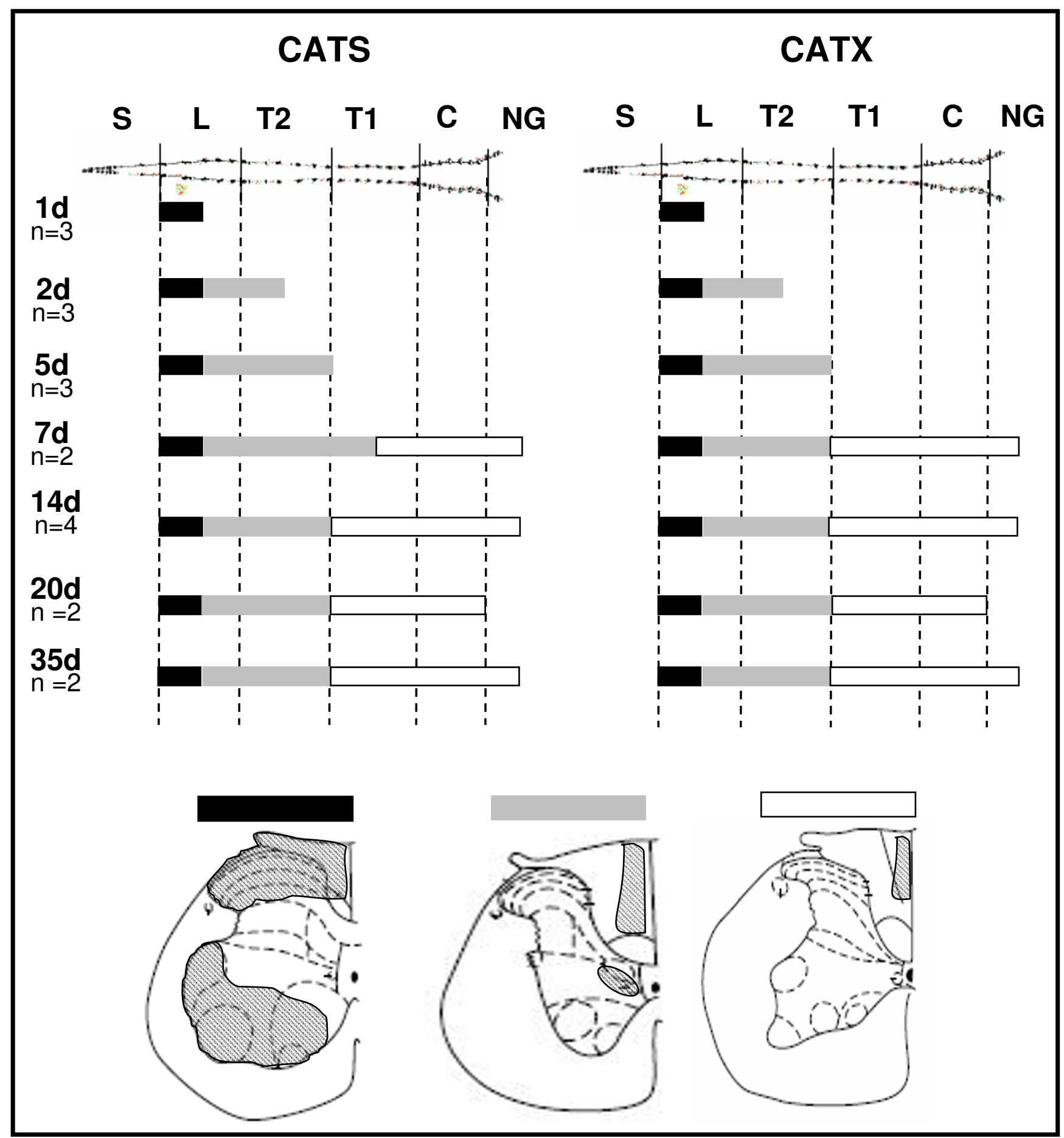

Figure 3

Spatiotemporal progression of CATS-/CATX-immunoreactivities in the spinal cord after L5T. Cranial progression of cathepsin upregulation during the first 5 weeks after transection. The different expression patterns in the transverse plane are symbolized by different fillings of the bars. Both cathepsins exhibited the same spatial and temporal distribution pattern up to $35 \mathrm{~d}$ after transection. 


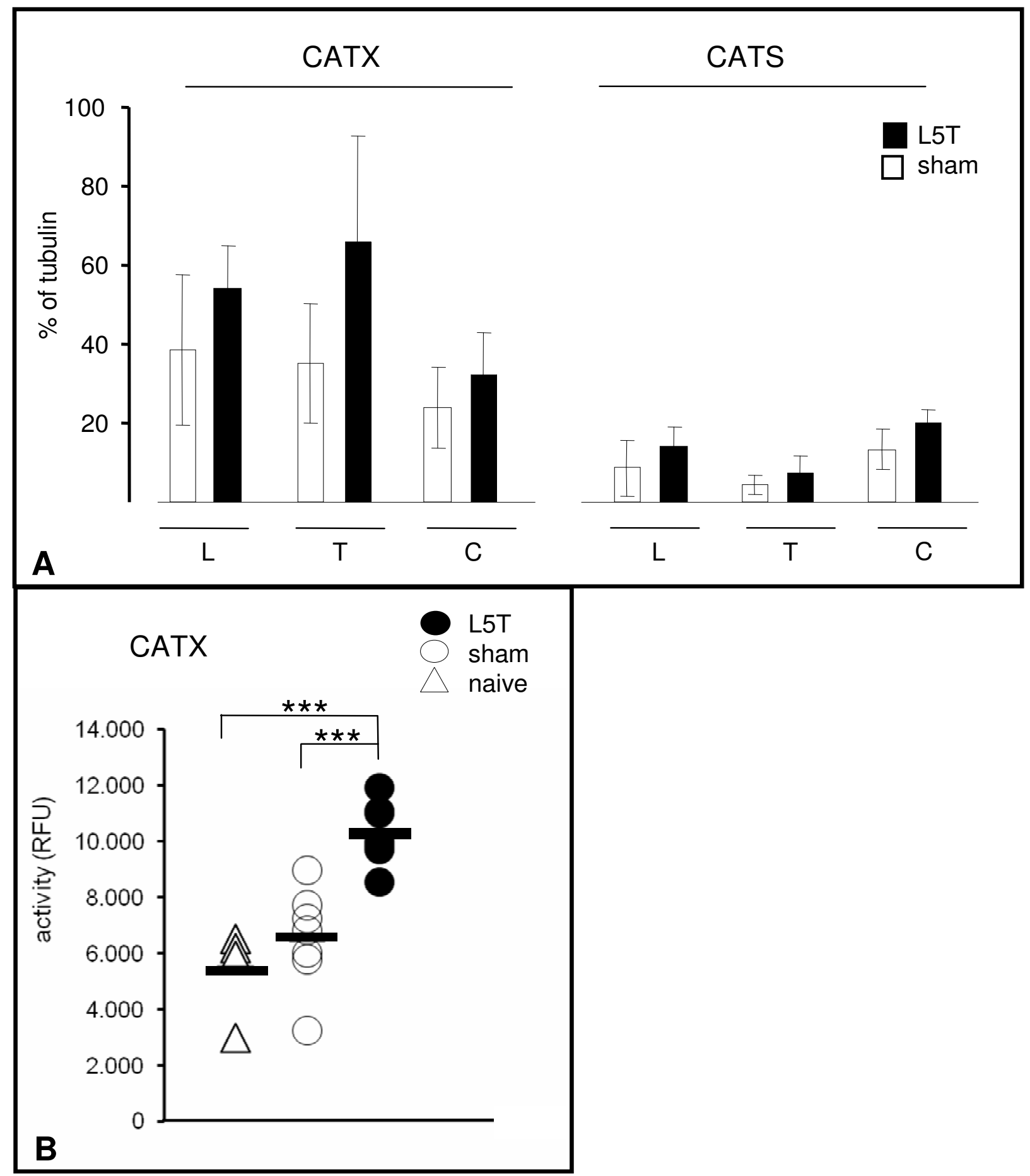

Figure 4

Upregulation of cathepsin protein levels and activities after L5T. A: Western blot analysis of CATX and CATS proform expression in the spinal cord of L5T $(n=5)$ and sham operated animals $(n=5)$ at $8 d$ after injury. Expression levels were normalized relative to the corresponding $\alpha$-tubulin band. At this time point the L5 transection induced an upregulation of both proteins in all SC segments. The expression level of CATX was substantially higher than that of CATS. Data are means \pm SD. B: CATX activities in the lumbar SC $8 \mathrm{~d}$ after transection in L5T, sham ( $=7$, for each group) and naive animals ( $\mathrm{n}=4$ ). Each symbol represents the value of a single animal, the bar indicates the mean for the group. CATX activity was significantly higher in L5T than in sham or naive SC. $* * * \mathrm{P} \leq 0.00 \mathrm{I}$. L, lumbar; C, cervical; $\mathrm{T}$, thoracic. 
to naive). CATB activity was not significantly changed (data not shown).

\section{Characterisation of CATS- and CATX-expressing cells}

Concurrent with the upregulation of CATS and CATX a strong gliosis appeared in the affected regions. In the ipsilateral fasciculus gracilis we observed numerous ED1immunopositive macrophages (Fig. 5A, B), while in the ipsilateral DH and VH PT66-immunopositive microglia and GFAP-immunopositive astrocytes were more abundant than in the contralateral side (Fig. 5C-H).

To determine the phenotype of CATS and CATX cells in vivo we performed double immunofluorescence. The majority of CATS-immunopositive cells expressed the microglia-marker PT66 or the astrocyte-marker GFAP (Fig. $\left.6 A^{\prime}-A^{\prime \prime \prime}\right)$, while only a small number of neurons were CATS-immunopositive (Fig. 6E). In contrast, CATXimmunoreactivity colocalizes only with single glial cells (Fig. 6B'-B"') but was more abundant in neurons (Fig. 6D). All ED1-immunopositive macrophages expressed both proteins (Fig. 6C'-C"').

\section{Discussion}

The dorsal spinal cord is the first relay station in sensory perception, which receives, transmits and modulates the signals from peripheral nerves. Recent research has uncovered that peripheral nerve injury triggers cascades of sys-

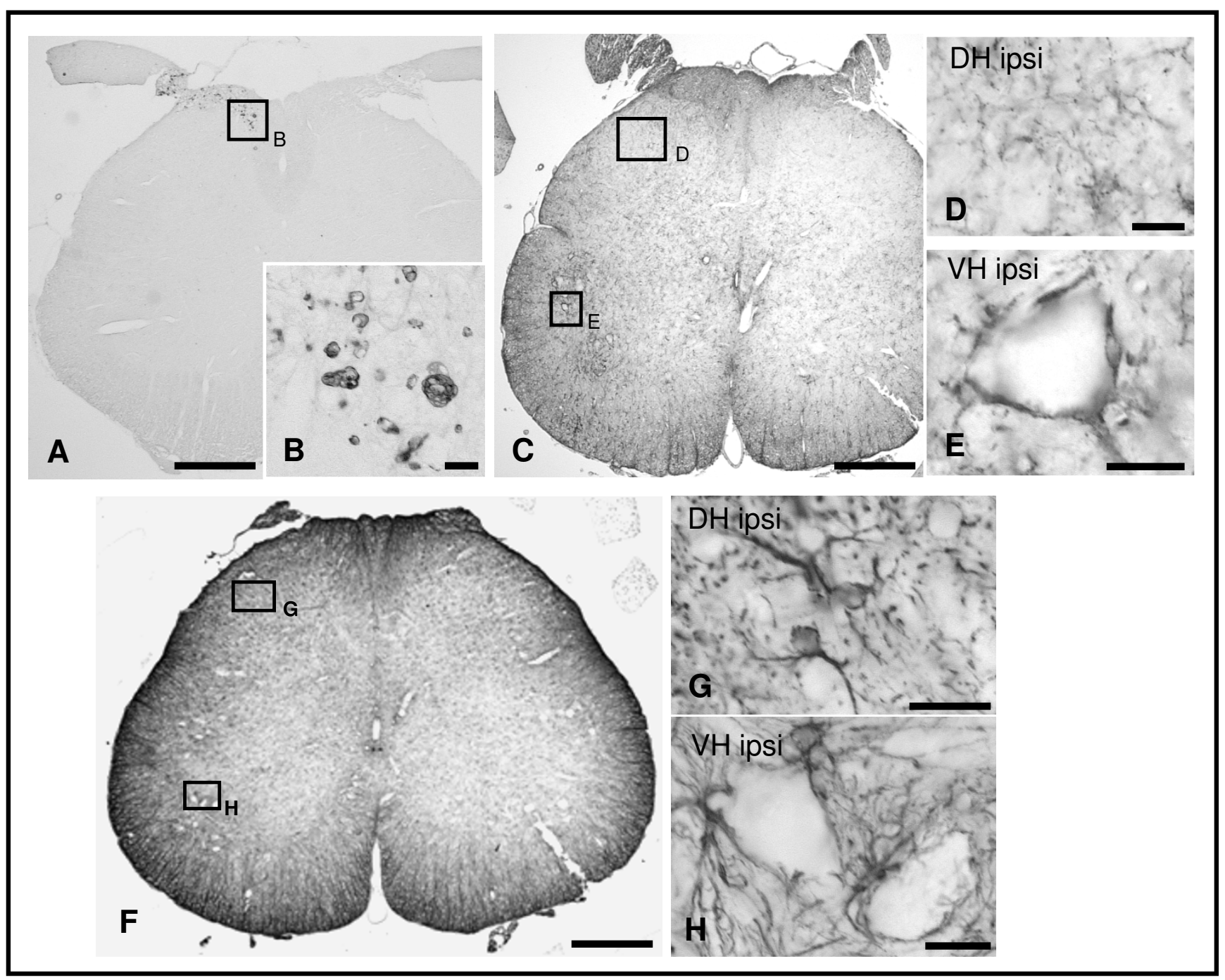

Figure 5

Reactive gliosis in the lumbar SC I4 d after L5 ligation and transection. ED I-immunopositive macrophages distributed within the fasciculus gracilis (A, B), while a higher density of PT66-immunopositive microglial cells (C-E) and GFAP-immunopositive astrocytes $(F-H)$ is also found in the ipsilateral dorsal (DH; D, G) and ventral horn $(V H ; E, H)$. Scale bars, $500 \mu m(A$, $C, F), 20 \mu \mathrm{m}(\mathrm{B}, \mathrm{D}, \mathrm{E}, \mathrm{G}, \mathrm{H})$. 


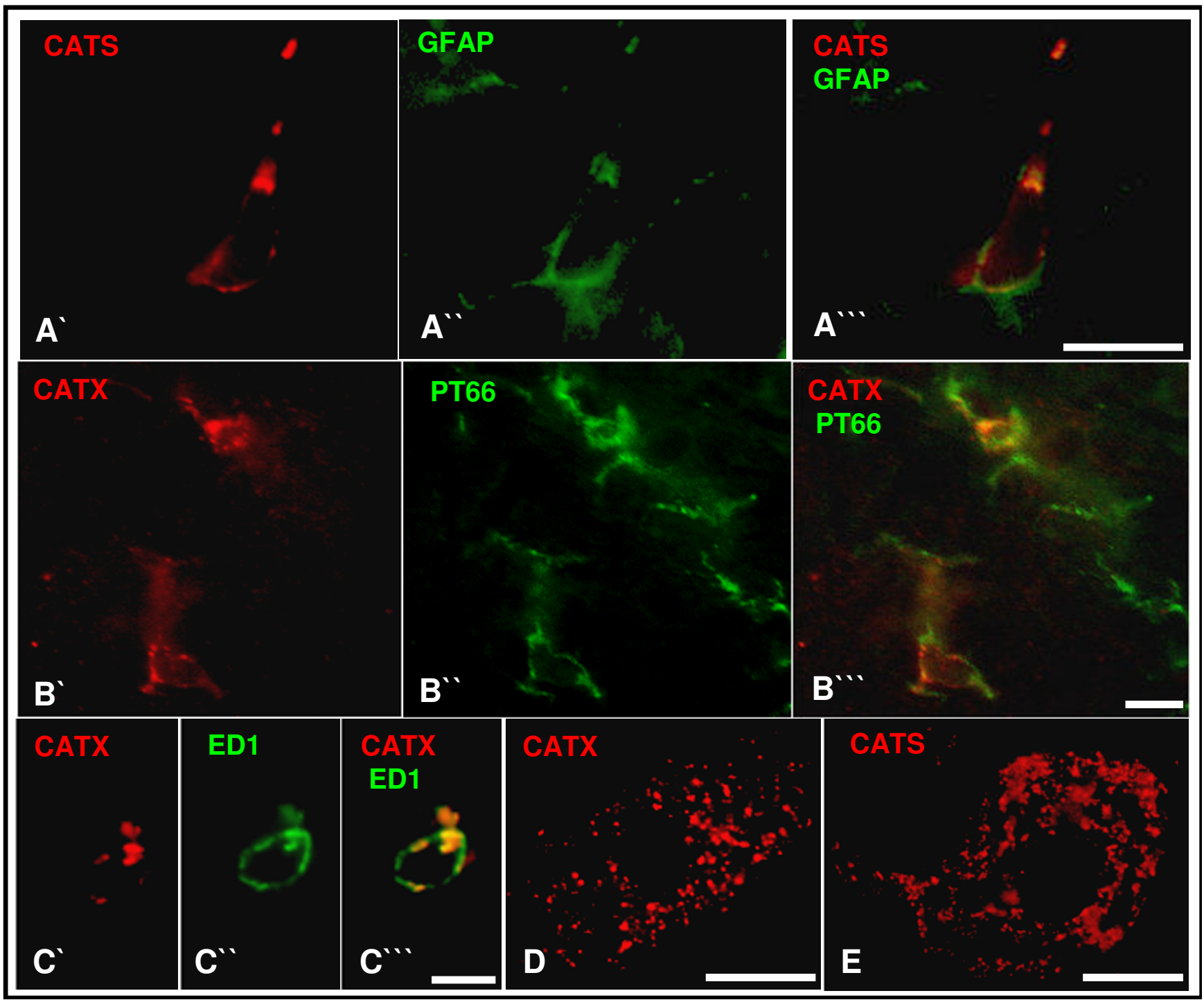

Figure 6

Phenotyping of CATS and CATX cells. Double-immunfluorescence of the spinal cord shows colocalization of CATS with the astrocyte marker GFAP ( $\left.A^{\prime}-A^{\prime \prime \prime}\right)$ and colocalization of CATX with the microglial marker PT66 (B'-B"') and the macrophage marker EDI ( $\left.C^{\prime}-C^{\prime \prime \prime}\right)$. Large motoneurons expressed CATX (D) and CATS (E). Scale bars, $10 \mu \mathrm{m}(A, B), 5 \mu \mathrm{m}(C), 20 \mu \mathrm{m}$ (D, E).

temic, cellular and molecular changes [4,33]. Moreover, there is ample evidence that these dynamic changes contribute to prolonged abnormal pain sensations. In the current study we analysed the participation of two cysteine proteases, the CATS and CATX, in the molecular processes underlying the induction and maintenance of neuropathic pain. Our results clearly show that immediately after surgery, concurrent to the onset of mechanical allodynia, both proteases, CATS and CATX, are upregulated in the spinal cord. Moreover, the upregulation of CATX protein was accompanied by a substantial increase in activity. In contrast to the increase in the proform level that of the
CATX activity was highly significant. This apparent contradiction might be explained by either an increase of the active form of CATX, that is still below the detection level of the Western Blot, or a concomitant regulation of endogenous cathepsin inhibitors, the cystatins or thyropins $[34,35]$. In fact there is recent evidence in favor of the idea that the cathepsin inhibitors are also regulated during persistent pain states [36].

Both, CATS and CATX, are widely expressed in the brain [26] and have been implicated in several neurological conditions such as Alzheimer's disease [26,37,38], amyo- 
trophic lateral sclerosis $[26,27]$ and age-related inflammation [26]. Recently, CATS has also been implicated in neuropathic hyperalgesia and allodynia. Using the gene chip technology CATS mRNA was found to be upregulated in the ipsilateral L4 and L5 DRG in the PSL and CCI model [11], while in the SNL or L5T model, CATS mRNA expression was regulated in the DRG $[39,40]$ and in the spinal cord $[9,10]$. Extending the latter results, we were able to detect the regulation of CATS protein levels and added a new cathepsin, CATX, to the list of regulated proteases in pain pathology.

Our immunohistochemical analysis, following the temporal development of neuropathic pain, supports the view that the upregulation of CATS and CATX expression is dynamic and proceeds along the fasciculus gracilis up to the medulla oblongata. Immediately $(1 \mathrm{~d})$ after transection CATS and CATX expressions increase. For both proteins this increase is restricted to the fasciculus gracilis, the dorsal horn and the layer IX in the ventral horn in the lumbar segment. As early as $2 \mathrm{~d}$ after injury the upregulation in the fasciculus gracilis spread cranially and reached the gracile nucleus at $1 \mathrm{w}$ after injury. At that time point this nucleus exhibited morphological signs of degeneration. We never found cathepsin upregulation on the contralateral side of the lesion or in sham operated animals. This characteristic spatio-temporal pattern suggests that the upregulation of CATS/X expression accompanies the degenerative process of the transected axons [41].

Whether the cathepsins contribute to the mechanism of degeneration and are causally involved in the pain processing or whether the differential expression is an epiphenomenon is difficult to answer on the basis of the data provided here. However, there is recent evidence that CATS is directly involved in the pain process by modulating the cytokine response [28]. Cathepsins display rather diverse physiological actions. CATS for instance is well recognized for its crucial function in the control of antigen presentation [31] and its role in the degradation of the extracellular matrix. In contrast to CATS, little is known about the physiological function of CATX. But the high expression of CATX in antigen-presenting monocytes/ macrophages [42,43], glial cells [26] and dendritic cells [32], its upregulation in the gastric mucosa of patients with Helicobacter pylori gastritis [44] and in the plasma of patients with multiple trauma [45] as well as its involvement in the production of bradykinin potentiating peptide [46] also imply a role in inflammatory processes.

\section{Conclusion}

Our results suggest a strong regulation of both, CATS and CATX, in the spinal cord of an animal model of neuropathic pain. Whether the cathepsins contribute to the mechanism of degeneration and are causally involved in the pain processing or whether the differential expression is an epiphenomenon is difficult to answer on the basis of the data provided here. Further experiments such as application of specific cathepsin inhibitors are required before the exact role of single cathepsin subtypes in the pain process can be unraveled.

\section{Methods \\ Surgery}

Male Wistar rats (Janvier, Le Genest Saint Isle, France) with a weight of $200-250 \mathrm{~g}$ were used. Animals were housed in a climate-controlled room on a 12-12 lightdark cycle. Food and water were available ad libitum. All procedures were approved by the local animal usage committees according to German guidelines on animal care and use.

Prior to the operation, rats were deeply anesthetized with pentobarbitone at a dose of $50 \mathrm{mg} / \mathrm{kg}$ i.p. The L5T model was achieved by transection of the left L5 spinal nerve in a procedure modified from Kim and Chung $[47,48]$. In sham controls the sciatic nerve was exposed but not transected.

Rats were sacrificed at day 1 ( $1 \mathrm{~d})-35 \mathrm{~d}$ for Western Blot analysis (L5T $\mathrm{n}=5$, sham $\mathrm{n}=5$ ), immunohistochemistry (L5T $\mathrm{n}=2-4$, sham $\mathrm{n}=4$ ) and activity assays (L5T $\mathrm{n}=4$, sham $\mathrm{n}=7$, naïve $\mathrm{n}=4$ ).

\section{Behavioral tests}

Withdrawal tests for evaluation of tactile allodynia were measured by the use of the dynamic plantar aesthesiometer. The animals were placed into raised plexiglass boxes with mesh flooring and allowed to acclimatize for at least 15 min until exploratory behavior ceased. Sampling was conducted by a metal filament which was applied manually to the ventral mid-plantar hind paw. The force raised $(0-50 \mathrm{~g})$ with time $(20 \mathrm{~s})$ until the rat lifted its paw. The mean withdrawal threshold for both hind paws was taken from a set of three applications, not less than 2 min apart.

\section{Tissue preparation}

For immunoblotting, spinal cord and brain tissues were homogenized in triple detergent lysis buffer $(50 \mathrm{mM}$ HEPES pH 7.4, $150 \mathrm{mM} \mathrm{NaCl}, 10 \mathrm{mM}$ EDTA, $1 \%$ Nonidet P40, $0.5 \%$ sodium deoxycholate, $0.1 \%$ sodium dodecyl sulfate, complete protease inhibitor cocktail (Roche Applied Science, Mannheim, Germany) using a Teflon/ glass homogenizer at $4{ }^{\circ} \mathrm{C}$. Homogenized samples were kept on ice for $30 \mathrm{~min}$ und subsequently centrifuged for $10 \mathrm{~min}$ in a precooled centrifuge at $12,000 \mathrm{~g}$. The supernatant was collected and subsequently diluted $1: 1$ in $2 \times$ Laemmli sample buffer and boiled for $5 \mathrm{~min}$. Protein determination was performed by the method of Neuhoff and coworkers [49]. 
For immunohistochemistry, animals were transcardially perfused with phosphate-buffered saline (PBS) followed by $4 \%$ paraformaldehyde (PFA) in $0.1 \mathrm{M}$ phosphate buffer (PB). The brain, the spinal cord and the ipsi- and contralateral nerves L4-L6 were excised and postfixed for $24 \mathrm{~h}$ in the perfusion fixative. Spinal cords were subdivided into the spinal cord segments according to the numbers of the related spinal nerves and all segments and the L5 (ipsi- and contralateral) nerves were embedded in paraffin. Serial, transversal $18-\mu \mathrm{m}$-thick sections were cut throughout all spinal cord segments, the hindbrain and the peripheral nerves. Sections were mounted on Superfrost slides (Carl Roth, Karlsruhe, Germany).

For CATX activity assays, the tissues were thawed separately on ice and homogenized in 7 -fold volume $(\mathrm{w} / \mathrm{v})$ of $100 \mathrm{mM} \mathrm{NaCl}, 50 \mathrm{mM} \mathrm{NaOAc}, 4 \mathrm{mM}$ EDTA-Na ${ }_{2}, 0.1 \%$ Triton X-100, pH 5.0 [50]. All procedures were carried out at $4{ }^{\circ} \mathrm{C}$. After incubating the samples for $60 \mathrm{~min}$ on ice, they were centrifuged ( $60 \mathrm{~min}$ at $13,000 \mathrm{~g}$ ) for elimination of debris. Supernatants were stored in aliquots at $80^{\circ} \mathrm{C}$ until further use. Protein contents of the preparations were measured by the method of Neuhoff [49].

\section{Western blots}

Proteins were electrophoretically separated on a $10 \%$ polyacrylamide gel containing SDS and transferred onto a PVDF-membrane (Carl Roth, Karlsruhe, Germany) at $4^{\circ} \mathrm{C}$ with $200 \mathrm{~mA}$ for $1.5 \mathrm{~h}$. Blocking was performed with $1.5 \%$ milk powder and 1\% BSA in TBS-Tween $(0.1 \%$ Tween, 20 $\mathrm{mM}$ TBS) at RT for $1 \mathrm{~h}$. Incubation with the primary antibodies goat anti-mouse CATX (1:500; R\&D Systems, Wiesbaden, Germany) or goat anti-human CATS (1:200; R\&D Systems) was conducted in blocking buffer overnight at $4{ }^{\circ} \mathrm{C}$. The next day blots were incubated in HRP-coupled anti-goat (1:50,000 in 1.5\% milk powder in TBS-Tween; Amersham Biosci., München, Germany) at RT for $1.5 \mathrm{~h}$, followed by detection with the ECL-Plus system (Amersham Biosci.).

To control protein loading, the blots were incubated with mouse anti-chick $\alpha$-tubulin (1:400,000; Sigma, Deisenhofen, Germany) followed by HRP-coupled anti-mouse (1:50,000 in 1.5\% milk powder in TBS-Tween; Amersham Biosci.) and the ECL-Plus system as described above.

\section{Immunohistochemistry}

Antibodies

Primary antibodies were used to document CATS and CATX and to identify the cathepsin-expressing cells. We used the following antibodies: goat anti-rat CATS (antiCATS; 1:100-200, Santa Cruz Biotechnology, Santa Cruz, USA suitable for detection of prepro-, pro- and mature form of CATS); goat anti-mouse CATX (anti-CATX; 1:100-200; R\&D systems, Abingdon, UK; suitable for detection of prepro-, pro- and mature form of CATX), the microglia/macrophage marker mouse anti-phosphotyrosine (anti-PT66; 1:1000; Sigma), the astrocyte marker mouse anti-glial fibrillary acidic protein (anti-GFAP; 1:2500-5000; Chemicon, Hampshire UK) and the macrophage marker mouse anti-rat CD68 (anti-ED1; 1:5000; Serotec, Düsseldorf, Germany).

\section{Stainings}

Single immunohistochemical stainings were performed on deparaffinized sections after antigen retrieval $(5 \mathrm{~min}$ cooking in $0.01 \mathrm{M}$ citrate buffer $\mathrm{pH} \mathrm{6.0,} \mathrm{for} \mathrm{all} \mathrm{primary}$ antibodies except ED1). Following the first antiserum incubations, sections were treated by the corresponding biotinylated secondary antibody (Axxora, Lörrach, Germany), and the ABC reagent (Axxora). Peroxidase reaction was carried out with 3,3'-diaminobenzidine as the chromogene and intensified with silver-gold [51]. Specificity of the stainings was either confirmed by omitting primary antibodies or by preabsorption with a five-fold (by weight) excess of specific blocking peptides for $2 \mathrm{~h}$ at RT (for anti-CATS and anti-CATX) (Fig. 1G and 1I).

Immunofluorescence double IHC was performed on deparaffinized sections after antigen retrieval. Therefore, we labeled sections simultaneously with primary antibodies and subsequently incubated them with biotinylated secondary antibody (1:300; Axxora) followed by fluorescein isothiocyanate-labeled Avidin (1:400; Axxora) and CY3-labeled secondary antibody (1:500; Dianova, Hamburg, Germany).

\section{CATX activity assay}

Spinal cord tissues were used for CATX enzyme activity tests. CATX activity was measured in $25 \mathrm{mM} \mathrm{CH}_{3} \mathrm{COONa} /$ $1 \mathrm{mM}$ EDTA/5 mM DTT (pH 3.5) with $10 \mu \mathrm{M}$ MCA-R-PP-G-F-S-A-F-K(Dnp)-OH (R\&D Systems) as substrate. In parallel assays, the specific CATB inhibitor CA-074 $(1 \mu \mathrm{M}$, Bachem, Weil am Rhein, Germany; Ki = $2 \mathrm{nM}$ for purified rat CATB and 40-200 $\mu \mathrm{M}$ for CATH and CATL; [52]) and the non-specific cysteine protease inhibitor E-64 (5 $\mu \mathrm{M}$, Sigma) were added in order to distinguish between CATB activity and the entire cysteine protease activity. A clear determination of CATB activity is essential as CATB is also able to hydrolyze the substrate at these conditions. Activity of other proteases being able to cleave MCA-R-P-P-GF-S-A-F-K(Dnp)-OH, like CATL and ECE-1, was undetectable (data not shown). Assays were performed at RT in black 96 multiwell plates (Falcon) in a total volume of 50 $\mu \mathrm{l}$. Prior starting the assay by addition of substrate, the enzyme solutions were pre-incubated for $5 \mathrm{~min}$ with the different inhibitors or diluent at RT. After a $30 \mathrm{~min}$ incubation time the assays were stopped by the addition of 50 $\mu \mathrm{l}$ stop solution $\left(100 \mathrm{mM} \mathrm{CH}_{2} \mathrm{ClCOOH}, 70 \mathrm{mM}\right.$ $\left.\mathrm{CH}_{3} \mathrm{COOH}, 30 \mathrm{mM} \mathrm{CH}_{3} \mathrm{COONa}, \mathrm{pH} 4.3\right)$ and measured 


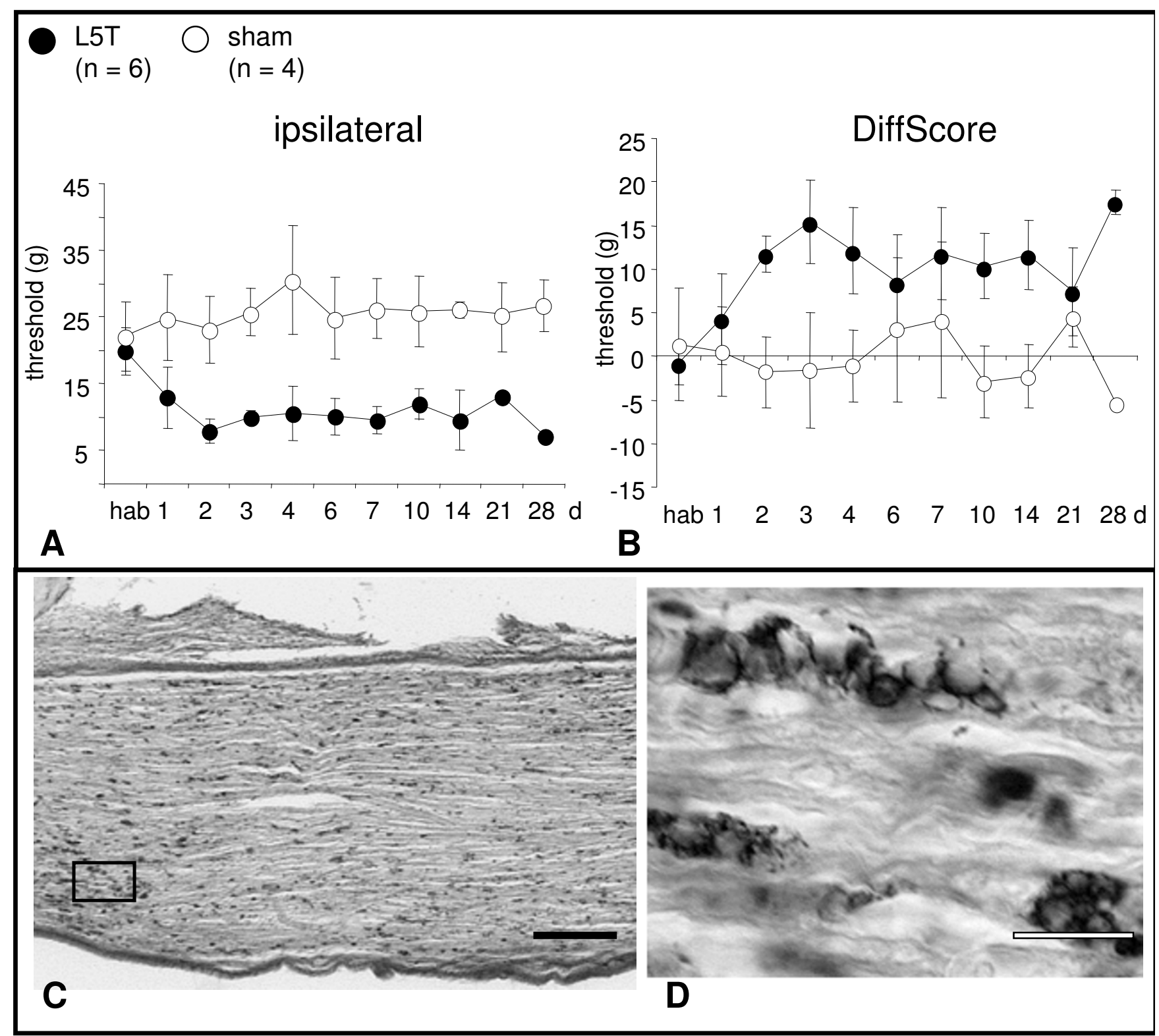

Figure 7

Behavior and histopathology after L5 transection. A, B: Time course of neuropathic mechanical allodynia in the ipsilateral hind paw expressed as ipsilateral threshold $(A)$ and Diffscore $(B$, difference between contralateral and ipsilateral withdrawal threshold) in L5T and sham operated animals. The L5T lesion led to a pronounced mechanical allodynia for up to 28 d. C, D: Representative example of ED I-immunostained proximal stump of transected L5 at I4 d after injury. The whole stump is densely filled with EDI-immunopositive macrophages (C) aligning along the trajectory of the axons (D). hab, habituation. Scale bars, $200 \mu \mathrm{m}(\mathrm{C})$ and $20 \mu \mathrm{m}$ (D).

at $340 / 430 \mathrm{~nm}$, according to the procedures described by [53]. The activities of the proteases were calculated on the basis of relative fluorescent units. The total cathepsin activity was assessed by taking the difference between non-inhibited and E-64 inhibited samples. CATB activity corresponded to the part of the response that could be inhibited by CA-074. The difference between the fluores- cence measured in the presence of the CATB inhibitor and the fluorescence measured in the presence of E-64 was attributed to CATX activity. 


\section{Data analysis}

Animals

Animals included in the present study fulfilled the following behavioral and anatomical criteria: (i) strong mechanical allodynia measured by the aesthesiometer and defined as an ipsilateral threshold difference between preand post-surgery of at least $5 \mathrm{~g}$ (Fig. 7A) and a DiffScore (contralateral threshold minus ipsilateral threshold) of a minimum of $5 \mathrm{~g}$ (Fig. 7B) and (ii) persistent L5 transsection (short survival times) and/or infiltration of L5 by numerous ED1-immunopositive macrophages (long survival times) (Fig. 7C, D).

\section{Western blots}

Band intensities were quantified using the analysis software TINA 2.09 (raytest Isotopenmeßgeräte $\mathrm{GmbH}$, Straubenhardt, Germany) and normalized relative to the intensity of the corresponding $\alpha$-tubulin bands. All data are presented as relative percentage of the means $\pm \mathrm{SD}$. Statistical significance was determined using the Student's t-test. P-values of less than 0.05 were considered to be statistically significant.

\section{Immunohistochemical stainings}

Peroxidase-labeled immunohistochemistry sections were visualized at the microscopic level (Axioskop2; Zeiss, Oberkochen, Germany) under brightfield illumination and Nomarski optics, while fluorescent structures were analyzed by epifluorescence (Axioskop2). Structures were identified with the aid of the atlas of [54]. The anatomic terminology used in this study is based on this atlas. Images were captured with an imaging system (JVC, KYF75U camera) connected to a computer equipped with an image program (Diskus 4.50, Hilgers, Königswinter, Germany).

Alterations of staining intensity or distribution of stained structures of each animal were independently analysed by two examiners blind with respect to the treatment of the animals.

\section{Cathepsin activity}

Data obtained from the CATX activity assays were analyzed by means of one-way ANOVA to determine statistical significance. All pairwise multiple comparison procedures were performed by Tukey's post hoc test.

\section{Abbreviations}

C: cervical; CATS: cathepsin S; CATX: cathepsin X; DH: dorsal horn; DRG: dorsal root ganglia; FG: fasciculus gracilis; L: lumbar; L5: $5^{\text {th }}$ lumbar nerve; L5T: ligation and transection of L5; NG: nucleus gracilis; SC: spinal cord; T: thoracic; $\mathrm{VH}$ : ventral horn.

\section{Authors' contributions}

$\mathrm{AL}$ and IB carried out the L5T surgeries and behavioral analysis, the immunohistochemical analysis and the activity assays; WW established the activity assays; MA helped with L5T surgeries; BS identified the cathepsin overexpression and performed preliminary experiments; CCS and HL conceived the study and oversaw all components including manuscript preparation. All authors read and approved the final manuscript.

\section{Additional material}

\section{Additional file 1}

Upregulation of cathepsin protein levels after L5T. Western blot analyses of CATX and CATS proform expression in the spinal cords of sham $(n=$ 5) and L5T ( $n=5)$ operated rats at $8 d$ after injury. Cervical, thoracic and lumbar segments were analyzed. Each band represents a single animal. C, cervical; T, thoracic; L, lumbar.

Click here for file

[http://www.biomedcentral.com/content/supplementary/14712202-9-80-S1.pdf]

\section{Additional file 2}

Quantification of Western blot analyses. Quantification of Western blot analyses of CATX and CATS proform expression in the spinal cord of L5T $(n=4)$ and sham operated animals $(n=4)$ (repetition of the experiment $\# 1$ - shown in the paper). Expression levels were normalized relative to the corresponding $\alpha$-tubulin band. Similar to experiment \#1 - the histogramms show an upregulation of both cathepsins in all SC segments. C, cervical; $T$, thoracic; L, lumbar.

Click here for file

[http://www.biomedcentral.com/content/supplementary/14712202-9-80-S2.pdf]

\section{Acknowledgements}

The authors thank Hildegard Degel, Petra Jergolla, Renate Scholl and Katrin Schuster for excellent technical assistance. This work was supported by DFG Graduiertenkolleg 736: Development and Plasticity of the Nervous System: Molecular, Synaptic and Cellular Mechanisms.

\section{References}

I. Campbell JN, Meyer RA: Mechanisms of neuropathic pain. Neuron 2006, 52:77-92.

2. Merskey $\mathrm{H}$, Bogduk $\mathrm{N}$ : Classification of chronic pain: descriptions of chronic pain syndromes and definitions of pain terms.Report by the International Association for the Study of Pain Task Force on Taxonomy. 2nd ed Seattle: IASP Press 1994.

3. Moalem G, Tracey DJ: Immune and inflammatory mechanisms in neuropathic pain. Brain Res Rev 2006, 5 1:240-264.

4. Bridges D, Thompson SW, Rice AS: Mechanisms of neuropathic pain. Br J Anaesth 200I, 87: I2-26.

5. Ji RR, Suter MR: p38 MAPK, microglial signaling, and neuropathic pain. Mol Pain 2007, 3:33.

6. Thacker MA, Clark AK, Marchand F, McMahon SB: Pathophysiology of peripheral neuropathic pain: immune cells and molecules. Anesth Analg 2007, 105:838-847.

7. McMahon SB, Cafferty WB, Marchand F: Immune and glial cell factors as pain mediators and modulators. Exp Neurol 2005, 1 92:444-462.

8. Kawasaki Y, Xu ZZ, Wang X, Park JY, Zhuang ZY, Tan PH, Gao YJ, Roy K, Corfas G, Lo EH, Ji RR: Distinct roles of matrix metallo- 
proteases in the early- and late-phase development of neuropathic pain. Nat Med 2008, 14:33I-336.

9. Griffin RS, Costigan M, Brenner GJ, Ma CH, Scholz J, Moss A, Allchorne AJ, Stahl GL, Woolf CJ: Complement induction in spinal cord microglia results in anaphylatoxin C5a-mediated pain hypersensitivity. J Neurosci 2007, 27:8699-8708.

10. Lacroix-Fralish ML, Tawfik VL, Tanga FY, Spratt KF, DeLeo JA: Differential spinal cord gene expression in rodent models of radicular and neuropathic pain. Anesthesiology 2006, 104:1283-1292

II. Barclay J, Clark AK, Ganju P, Gentry C, Patel S, Wotherspoon G, Buxton F, Song C, Ullah J, Winter J, Fox A, Bevan S, Malcangio M: Role of the cysteine protease cathepsin $S$ in neuropathic hyperalgesia. Pain 2007, 1 30:225-234.

12. Bunnett NW: Protease-activated receptors: how proteases signal to cells to cause inflammation and pain. Semin Thromb Hemost 2006, 32 Suppl I:39-48.

13. Turk B: Targeting proteases: successes, failures and future prospects. Nat Rev Drug Discov 2006, 5:785-799.

14. Hollenberg MD: Proteinase-mediated signaling: proteinaseactivated receptors (PARs) and much more. Life Sci 2003, 74:237-246

15. Agrawal SM, Lau L, Yong VW: MMPs in the central nervous system: where the good guys go bad. Semin Cell Dev Biol 2008, 19:42-51.

16. Festjens N, Cornelis S, Lamkanfi M, Vandenabeele P: Caspase-containing complexes in the regulation of cell death and inflammation. Biol Chem 2006, 387:1005-1016.

17. Nixon RA, Cataldo AM: The lysosomal system in neuronal cell death: a review. Ann N Y Acad Sci 1993, 679:87-109.

18. Turk B, Turk D, Turk V: Lysosomal cyteine proteases: more than scavengers. Biochem Biophys Acta 2000, I 477:98-III

19. Deussing J, Kouadio M, Rehman S, Werber I, Schwinde A, Peters C: Identification and characterization of a dense cluster of placenta-specific cysteine peptidase genes and related genes on mouse chromosome 13. Genomics 2002, 79:225-240.

20. Roberts R: Lysosomal cysteine proteases: structure, function and inhibition of cathepsins. Drug News Perspect 2005, | 8:605-6|4.

21. Stoka V, Turk B, Turk V: Lysosomal cysteine proteases: structural features and their role in apoptosis. IUBMB Life 2005, 57:347-353.

22. Bernstein HG, Bruszis S, Schmidt D, Wiederanders B, Dorn A Immunodetection of cathepsin $D$ in neuritic plaques found in brains of patients with dementia of Alzheimer type. J Hirnforsch 1989, 30:6|3-618.

23. Bernstein HG, Wiederanders B: An immunohistochemical study of cathepsin E in Alzheimer-type dementia brains. Brain Res 1994, 667:287-290.

24. Cataldo AM, Hamilton DJ, Barnett JL, Paskevich PA, Nixon RA: Properties of the endosomal-lysosomal system in the human central nervous system: disturbances mark most neurons in populations at risk to degenerate in Alzheimer's disease. Neurosci 1996, 16:186-199.

25. Mantle D, Falkous G, Ishiura S, Perry RH, Perry EK: Comparison of cathepsin protease activities in brain tissue from normal cases and cases with Alzheimer's disease, Lewy body dementia, Parkinson's disease and Huntington's disease. J Neurol Sci 1995, I31:65-70.

26. Wendt $W$, Zhu XR, Lubbert H, Stichel CC: Differential expression of cathepsin $X$ in aging and pathological central nervous system of mice. Exp Neurol 2007, 204:525-540.

27. Wendt W, Lübbert H, Stichel CC: Cathepsin $S$ in aging and pathological nervous system of mice. in prep 2008.

28. Clark AK, Yip PK, Grist J, Gentry C, Staniland AA, Marchand F, Dehvari $M$, Wotherspoon G, Winter J, Ullah J, Bevan S, Malcangio M: Inhibition of spinal microglial cathepsin $\mathbf{S}$ for the reversal of neuropathic pain. Proc Natl Acad Sci U S A 2007, 104: I0655-10660.

29. Kirschke H, Schmidt I, Wiederanders B: Cathepsin S. The cysteine proteinase from bovine lymphoid tissue is distinct from cathepsin L (EC 3.4.22.15). Biochem J 1986, 240:455-459.

30. Turnsek T, Kregar I, Lebez D: Acid sulphydryl protease from calf lymph nodes. Biochim Biophys Acta 1975, 403:5 I4-520.

31. Thurmond RL, Sun S, Karlsson L, Edwards JP: Cathepsin S inhibitors as novel immunomodulators. Curr Opin Investig Drugs 2005, 6:473-482.
32. Stichel CC, Lübbert $\mathrm{H}$ : Inflammatory processes in the aging mouse brain: participation of dendritic cells and T-cells. Neurobiol Aging 2007, 28: I 507-I52।.

33. Lamont LA, Tranquilli W], Grimm KA: Physiology of pain. Vet Clin North Am Small Anim Pract 2000, 30:703-728.

34. Abrahamson M, Alvarez-Fernandez M, Nathanson CM: Cystatins. Biochem Soc Symp 2003:179-199.

35. Lenarcic B, Bevec $\mathrm{T}$ : Thyropins--new structurally related proteinase inhibitors. Biol Chem 1998, 379: 105-III.

36. Yang HY, Wilkening S, ladarola MJ: Spinal cord genes enriched in rat dorsal horn and induced by noxious stimulation identified by subtraction cloning and differential hybridization. Neuroscience 200I, 103:493-502.

37. Beglopoulos V, Sun X, Saura CA, Lemere CA, Kim RD, Shen J: Reduced beta-amyloid production and increased inflammatory responses in presenilin conditional knock-out mice. J Biol Chem 2004, 279:46907-469|4.

38. Lemere CA, Munger JS, Shi GP, Natkin L, Haass C, Chapman HA Selkoe DJ: The lysosomal cysteine protease, cathepsin $S$, is increased in Alzheimer's disease and Down syndrome brain. An immunocytochemical study. Am J Pathol 1995, 146:848-860.

39. Wang H, Sun H, Della PK, Benz RJ, Xu J, Gerhold DL, Holder DJ, Koblan KS: Chronic neuropathic pain is accompanied by global changes in gene expression and shares pathobiology with neurodegenerative diseases. Neuroscience 2002, I | 4:529-546.

40. Valder CR, Liu JJ, Song YH, Luo ZD: Coupling gene chip analyses and rat genetic variances in identifying potential target genes that may contribute to neuropathic allodynia development. J Neurochem 2003, 87:560-573.

4I. George R, Griffin JW: The proximo-distal spread of axonal degeneration in the dorsal columns of the rat. I Neurocytol 1994, 23:657-667.

42. Journet A, Chapel A, Kieffer S, Louwagie M, Luche S, Garin J: Towards a human repertoire of monocytic lysosomal proteins. Electrophoresis 2000, 21:34II-34I9.

43. Garin J, Diez R, Kieffer S, Dermine JF, Duclos S, Gagnon E, Sadoul R, Rondeau C, Desjardins M: The phagosome proteome: insight into phagosome functions. J Cell Biol 200I, I52:165-180.

44. Krueger S, Kalinski T, Hundertmark T, Wex T, Kuster D, Peitz $U$, Ebert M, Nagler DK, Kellner U, Malfertheiner P, Naumann M, Rocken $C$, Roessner A: Up-regulation of cathepsin $\mathbf{X}$ in Helicobacter pylori gastritis and gastric cancer. J Pathol 2005, 207:32-42.

45. Nagler DK, Lechner AM, Oettl A, Kozaczynska K, Scheuber HP, Gippner-Steppert C, Bogner V, Biberthaler P, Jochum M: An enzyme-linked immunosorbent assay for human cathepsin $\mathbf{X}$, a potential new inflammatory marker. J Immunol Methods 2006, 308:24I-250.

46. Sakamoto E, Sakao Y, Taniguchi Y, Yamafuji K: Cathepsin Y (a novel thiol enzyme) produces kinin potentiating peptide from the component protein of rat plasma. Immunopharmacology 1999, 45:207-2।4.

47. Kim SH, Chung J]: An experimental model for peripheral neuropathy produced by segmental spinal nerve ligation in the rat. Pain 1992, 50:355-363.

48. Ringkamp M, Eschenfelder S, Grethel EJ, Habler HJ, Meyer RA, Janig W, Raja SN: Lumbar sympathectomy failed to reverse mechanical allodynia- and hyperalgesia-like behavior in rats with L5 spinal nerve injury. Pain 1999, 79:143-153.

49. Neuhoff VPK, Zimmer HG, Mesecke S: A simple and vertsatile, sensitive and volume-independent method for quantitative protein determination with independence of other external influences,. Hoppe-Seyler's Z Physiol Chem 1979, 360:1657-1670.

50. Knoch H, Werle B, Ebert W, Spiess E: Imbalance between cathepsine $B$ and cysteine proteinase inhibitors is of prognostic significance in human lung cancer. Int J Oncology 1994, 5:77-85.

5I. Stichel CC, Singer W, Zilles K: Ultrastructure of PkC(II/III)immunopositive structures in rat primary visual cortex. Exp Brain Res 1990, 82:575-584

52. Towatari T, Nikawa T, Murata M, Yokoo C, Tamai M, Hanada K, Katunuma N: Novel epoxysuccinyl peptides. A selective inhibitor of cathepsin B, in vivo. FEBS Lett I991, 280:31I-315.

53. Barrett AJ, Kirschke H: Cathepsin B, Cathepsin H, and cathepsin L. Methods Enzymol I98I, 80 Pt C:535-56।.

54. Paxinos G, Franklin KBJ: The mouse brain in stereotaxic coordinates San Diego, Academic Press; 200I. 